\title{
Microbial and chemical composition of Cheddar cheese supplemented with prebiotics from pasteurized milk to aging
}

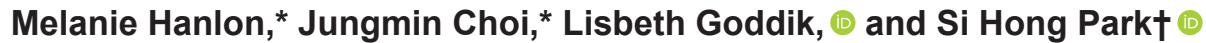 \\ Department of Food Science and Technology, Oregon State University, Corvallis 97331
}

\begin{abstract}
Microbial and chemical properties of cheese is crucial in the dairy industry to understand their effects on cheese quality. Microorganisms within this fat, protein, and water matrix are largely responsible for physiochemical characteristics and associated quality. Prebiotics can be used as an energy source for lactic acid bacteria in cheese by altering the microbial community and provide the potential for value-added foods, with a more stable probiotic population. This research focuses on the addition of fructooligosaccharides (FOS) or inulin to the Cheddar cheese-making process to evaluate the effects on microbial and physicochemical composition changes. Laboratory-scale Cheddar cheese produced in 2 replicates was supplemented with 0 (control), 0.5, 1.0, and 2.0\% (wt/wt) of FOS or inulin using $18 \mathrm{~L}$ of commercially pasteurized milk. A total of 210 samples (15 samples per replicate of each treatment) were collected from cheese-making procedure and aging period. Analysis for each sample were performed for quantitative analysis of chemical and microbial composition. The prevalence of lactic acid bacteria $(\log \mathrm{cfu} / \mathrm{g})$ in Cheddar cheese supplemented with FOS (6.34 \pm 0.11 and $8.99 \pm 0.46 ; \pm$ standard deviation) or inulin $(6.02 \pm 0.79$ and $9.08 \pm 1.00)$ was significantly higher than the control $(5.84 \pm 0.27$ and $8.48 \pm 0.06)$ in whey and curd, respectively. Fructooligosaccharides supplemented cheeses showed similar chemical properties to the control cheese, whereas inulin-supplemented cheeses exhibited a significantly higher moisture content than FOS and the control groups. Streptococcus and Lactococcus were predominant in all cheeses and $2 \%$ inulin and $2 \%$ FOS-supplemented cheeses possessed significant amounts of nonstarter lactic acid bacteria found to be an unidentified group of Lactobacillaceae, which emerged after $90 \mathrm{~d}$ of aging. In conclusion, this
\end{abstract}

Received August 16, 2021.

Accepted November 16, 2021.

*These authors contributed equally to this work.

†Corresponding author: sihong.park@oregonstate.edu study demonstrates that prebiotic supplementation of Cheddar cheese results in differing microbial and chemical characteristics.

Key words: prebiotics, Cheddar cheese, microbiome, chemical composition

\section{INTRODUCTION}

The Food and Agriculture Organization (FAO) reports that cheese consumption worldwide has increased by $5 \%$ last 4 years, and global cheese market revenue is anticipated to escalate to $\$ 124$ billion by 2022 (Gosalvitr et al., 2019). This FAO report attributes the majority of global cheese consumption to the European Union and North America, with per capita consumption expected to increase through 2028 (OECD-FAO, 2021). Of the many types of cheese, Cheddar and Mozzarella are the 2 most-consumed varieties per capita in the United States with a broad use in fast food settings, including for pasta, pizza, and sandwiches (Tejeda and Kim, 2021).

Lactic acid bacteria $(\mathbf{L A B})$ are part of numerous genus under the family of Lactobacillaceae and other families that utilize lactose to produce lactic acids. Lactic acid bacteria have a variety of applications in the fermented food industry for products such as yogurt, cheese, and sausage due to their status as generally recognized as safe (Widyastuti et al., 2014). Different selections of starter LAB (SLAB) allow for production of fermented dairy products with desired sensory properties, enhanced preservation, and nutritional benefits for health (Vinderola et al., 2002).

Although prebiotics are not broken down by human digestive enzymes, certain groups of beneficial bacteria in gastrointestinal tracts consume prebiotics for contributing selective growth and activity of microbes (AlSheraji et al., 2013). Prebiotics are primarily composed of carbohydrates and fibers, such as resistant starch, inulin, or oligosaccharides. Among them, fructooligosaccharides (FOS), or galactooligosaccharides, has been proven to selectively increase prevalence of lactobacilli and bifidobacteria, which are beneficial probiotics of the gastrointestinal microbiota (Gibson, 1998). Inulin is 
an indigestible carbohydrate, of a group known as fructans that contain glycosidic bonds composed mostly of fructosyl-fructose bonds. Inulin is popular in asparagus root, garlic, or chicory root as a form of carbohydrate storage (Rocha et al., 2006). An emerging approach is the combination of probiotics and prebiotics together as synbiotics in an effort to maximize synergistic effects of the two compounds through enhancing the probiotic colonization or metabolic effects (Roberfroid, 1998). Additionally, synbiotics have been proven to be more potent over probiotics or prebiotics alone toward positive regulation in the gut microbiota (Saulnier et al., 2008).

Understanding the chemical and microbial compositions of cheese is essential in the dairy industry, as specific microorganisms or chemical components in the product contribute to beneficial sensory aspects, whereas others may inversely contribute to off flavors or reduce quality via spoilage; this is of particular relevance in fermented and aged foods (Mayo et al., 2014). Development and optimization of high throughput sequencing (HTS) technology allows the acquisition of extensive genomic information at a low cost with high efficiency, having the potential to improve understanding of microbial properties of the specified matrix (Yeluri Jonnala et al. 2018). The advent of next-generation sequencing has allowed for a deeper understanding and exploration of microbial communities, or microbiomes, the combined genetic material of microorganisms within a particular environment. Next-generation sequencing serves as a reliable alternative to culture-dependent approaches for understanding the composition of cheese microorganisms (Choi et al., 2020a,b; Nam et al., 2021) and provides further detail about specific genus present in addition to organoleptic properties (Yeluri Jonnala et al. 2018). The HTS technique can indicate how microbes respond to cheese-making process, providing cheesemakers with enhanced control of microbial growth in their products based on assessments of parameters affecting the growth of beneficial and spoilage organisms (Solieri et al., 2013).

\section{MATERIALS AND METHODS}

In this study, we added commercial FOS or inulin to Cheddar cheese and analyzed the microbial and chemical properties during the manufacturing process starting with commercially pasteurized milk through the final product, aged for 3 mo. Samples collected at each stage were analyzed to evaluate the changes of the microbial community, chemical composition, and functional properties between Cheddar cheeses supplemented with different concentrations of FOS or inulin.

\section{Cheddar Cheese Making and Sampling}

The overall Cheddar cheese-making process is shown in Figure 1. Eighteen liters of pasteurized milk (sample milk) purchased at the local grocery store was mixed with $0.5,1$, and $2 \%$ (wt/vol) FOS or inulin. The SLAB mesophilic commercial starter series Choozit RA21 and MD88 (Danisco) containing Streptococcus spp. and Lactococcus spp. which were both included in the mesophilic starter cultures consisting of L. lactis ssp. lactis biovar diacetylactis, L. lactis ssp. lactis, L. lactis ssp. cremoris, and $S$. thermophilus were added at $1.6 \times$ $10^{6} \mathrm{cfu} / \mathrm{mL}$ and $2.0 \times 10^{6} \mathrm{cfu} / \mathrm{mL}$ into the pasteurized milk, respectively. One hour after SLAB inoculation into milk, samples were collected (sample 1-h culture), $0.01 \%$ rennet (vol/wt) was added and milk was allowed to coagulate for $45 \mathrm{~min}$. The coagulum was then cut into $1.0 \times 1.0$-inch cube-shaped curds, and then were simultaneously stirred and heated from 32 to $37^{\circ} \mathrm{C}$ for $45 \mathrm{~min}$. After this cook step, whey was slowly drained from curds ensuring the $\mathrm{pH} 6.3$ before allowing all whey to drain off, collecting a sample of the discarded whey (sample whey). The curd was then cut into proportional loaves with a knife and rest for 5 min. Then cheddaring was performed until the $\mathrm{pH}$ of the curds reached a value within the range of 5.3 to 5.4. After the addition of clarified salt (3.5\% wt/wt $\mathrm{NaCl} /$ total curd weight), a sample was collected (sample curd), and the curds were transferred to a mold and pressed for $16 \mathrm{~h}$ at room temperature (sample fresh). The pressed fresh cheese loaves were vacuum sealed and stored at $4{ }^{\circ} \mathrm{C}$ for 3 mo of aging. The cheese samples were collected for analysis directly during production, and 10, 20, 30, 60, and $90 \mathrm{~d}$ (sample aging), after the initial processing day. Each concentration of prebiotic and the control were produced in duplicate.

\section{Chemical Composition Analysis}

Samples of FOS or inulin-supplemented Cheddar cheese were collected after $90 \mathrm{~d}$ of aging for macronutrient component analysis of moisture, ash, fat, and protein content. All chemical composition samples were performed for d 90 of aging only. Each cheese sample (50 g) was homogenized in a stainless-steel blender (model 51BL32, Waring Commercial) until a uniform particle size was reached. Fat content was measured following to the Gerber Van Gulick method (ISO, 2008). Protein content was estimated using a combustion analyzer (vario MACRO cube, Elementar Analysensysteme $\mathrm{GmbH}$ ), and nitrogen analysis was performed according to the Dumas combustion method (Dumas, 1831). Crude protein was calculated by multiplying 
total nitrogen by a conversion factor of 6.38. Moisture content of cheese was determined from $5 \mathrm{~g}$ of ground cheese sample by oven drying at $120^{\circ} \mathrm{C}$ for $3 \mathrm{~h}$ under vacuum. Dried cheese samples (approximately $2 \mathrm{~g}$ ) were transferred to dry oven and heated at $550^{\circ} \mathrm{C}$ until completely ashed for $12 \mathrm{~h}$. Measurements were taken after ashing and subtracted from the initial dry weight to determine final ash content.

\section{LAB and Aerobic Plate Count}

For microbial composition analysis, pasteurized milk, milk $1 \mathrm{~h}$ after inoculation with SLAB, whey, curd, fresh cheese, and aged cheeses (10, 20, 30, 60, and $90 \mathrm{~d}$ ) were collected. Ten grams of Cheddar cheese and curd samples were homogenized with $90 \mathrm{~mL}$ of $2 \%$ tri-citric acid buffer $\left(\mathrm{C}_{6} \mathrm{H}_{7} \mathrm{Na}_{3} \mathrm{O}_{8}\right)$ and placed in sterile Stomacher 400 filter bags (Seward) to homogenize at $230 \mathrm{rpm}$ for 5 min using a stomacher (Seward). For viable cell counts within the cheese solution, samples were plated on de Man, Rogosa, and Sharpe (MRS) agar (Hardy Diagnostics) and incubated at $37^{\circ} \mathrm{C}$ anaerobically, and 3M Petrifilm Aerobic Count (3M Corp.) plates were incubated at $37^{\circ} \mathrm{C}$ aerobically.

\section{DNA Extraction}

To prepare a homogeneous solution for DNA extraction, $30 \mathrm{~mL}$ of pasteurized milk, milk one hour after culture inoculation and whey samples were centrifuged at $4^{\circ} \mathrm{C}, 13,000 \times g$ for $5 \mathrm{~min}$, the lipid layer was removed with a loop, and the supernatant was discarded. The milk pellet was resuspended with $1.8 \mathrm{~mL}$ of water and centrifuged at $4^{\circ} \mathrm{C}, 13,000 \times g$ for $2 \mathrm{~min}$. The scraped lipid layer and supernatant were discarded. For cheese sample preparation, $10 \mathrm{~g}$ of cheese with $90 \mathrm{~mL}$ of $2 \%$ tri-citric acid buffer $\left(\mathrm{C}_{6} \mathrm{H}_{7} \mathrm{Na}_{3} \mathrm{O}_{8}\right)$ was homogenized with a stomacher (Seward) and incubated at 55 to $60^{\circ} \mathrm{C}$ until melted completely. The cheese solution $(1.8 \mathrm{~mL})$ was centrifuged at $4^{\circ} \mathrm{C}, 13,000 \times g$ for $2 \mathrm{~min}$, and the supernatant was discarded. The DNA from all cheese samples were isolated using a DNeasy PowerFood Microbial Kit (Qiagen), according to manufacturer's instruction. The extracted DNA concentration was measured using a Qubit 4 Fluorometer (Thermo Fisher Scientific) and subsequently diluted to $10 \mathrm{ng} / \mathrm{ul}$.

\section{S rRNA Library Preparation}

The sequencing library was constructed to target the V4 region of $16 \mathrm{~S}$ rRNA based on the previous report (Kozich et al., 2013). The DNA fragments were amplified using a high-fidelity polymerase (AccuPrime ${ }^{\mathrm{T}} \mathrm{Pfx}$ SuperMix, Thermo Fisher Scientific) and normalized using a SequalPrep Normalization Kit (Thermo Fisher Scientific) according to the manufacturer's recommendations. Following normalization, $5 \mu \mathrm{L}$ of each normalized aliquot were combined to construct 1 pooled library, and then performed for quantification using a KAPA Library Quantification Kit (Kapa Biosystems). Finally, the pooled library was diluted to $20 \mathrm{n} M$ before sequencing via a MiSeq (Illumina).

\section{Microbiome Sequencing via Illumina MiSeq Platform}

Each of the $20 \mathrm{n} M$ of pooled library and $20 \mathrm{n} M$ of PhiX control v3 (Illumina) were diluted with $0.2 N$ fresh $\mathrm{NaOH}$ and HT1 buffer (Illumina) to produce the final concentration at $7.8 \mathrm{p} M$. The diluted library was mixed with the PhiX control v3 (10\%, vol/vol, Illumina) and

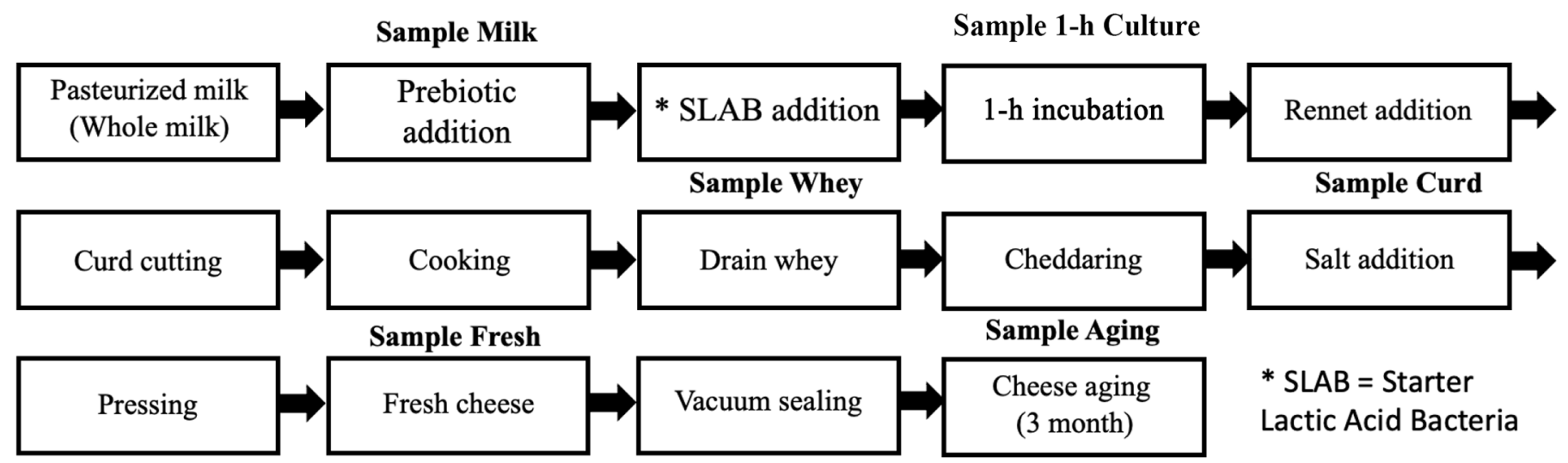

Figure 1. Flowchart for manufacturing and sampling stages during Cheddar cheese production. 


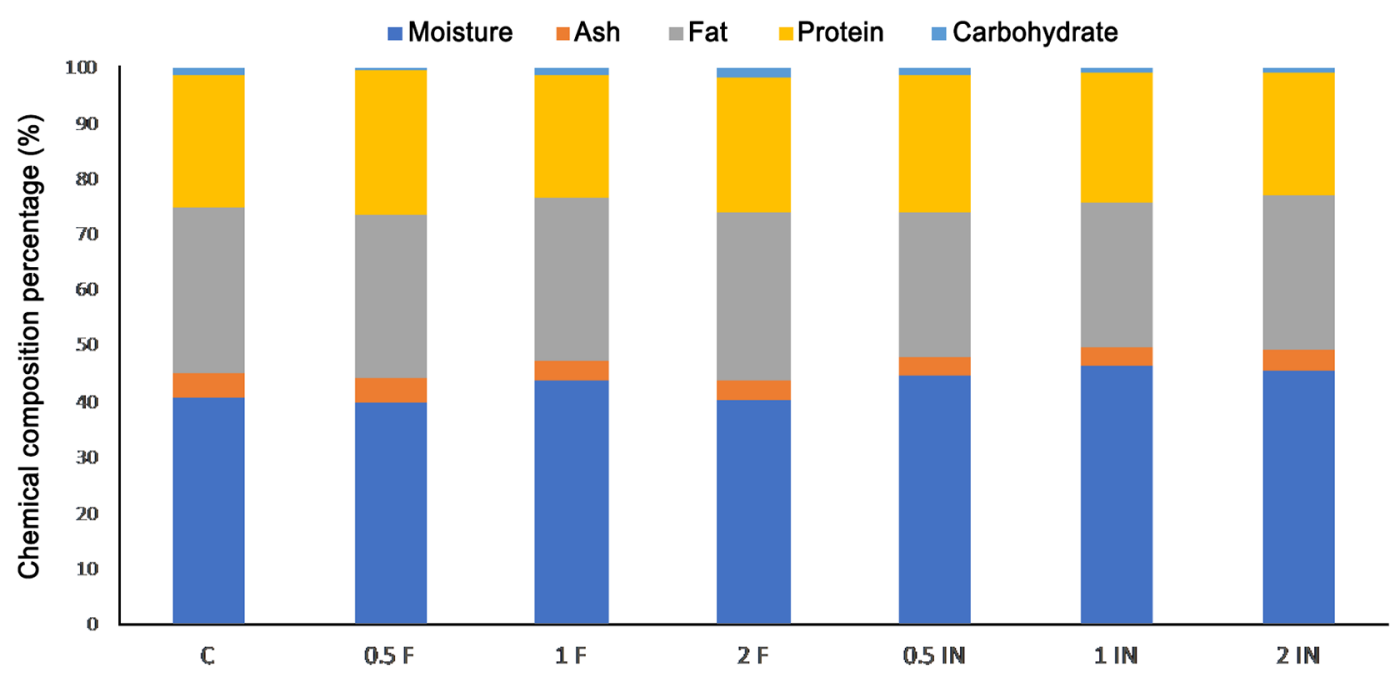

Figure 2. Chemical composition of the control and each Cheddar cheese supplemented with the prebiotics fructooligosaccharide (FOS) or inulin at $0.5,1.0$, and $2.0 \%$ (wt/wt). Samples for chemical analysis were collected after $90 \mathrm{~d}$ of aging. Treatments: $\mathrm{C}=$ control; $0.5 \mathrm{~F}=0.5 \%$ FOS; $1 \mathrm{~F}=1 \%$ FOS; $2 \mathrm{~F}=2.0 \%$ FOS; $0.5 \mathrm{IN}=0.5 \%$ inulin; $1 \mathrm{IN}=1.0 \%$ inulin; $2 \mathrm{IN}=2.0 \%$ inulin.

$600 \mu \mathrm{L}$ was loaded on a MiSeq v2 $(2 \times 250 \mathrm{bp}, 500$ cycle) reagent cartridge for sequencing.

\section{Data Analyses}

Both demultiplexed $\mathrm{R} 1$ and $\mathrm{R} 2$ raw sequences were acquired directly from the Illumina BaseSpace (https:/ /basespace.illumina.com/dashboard) and analyzed using a Quantitative Insights into Microbial Ecology 2 (QIIME 2, version 2020.06) open source pipeline (Bolyen et al., 2019). Demultiplexed sequences were joined together and denoized for quality control via DADA2 scripts available in QIIME 2 to make a feature table. To perform further statistical analysis and visualization, an operational taxonomic unit (OTU) table and metadata files were uploaded to the MicrobiomeAnalyst, available at http://www.microbiomeanalyst.ca (Dhariwal et al., 2017). Additionally, the functional contents of microbiome data from different types of cheese samples was predicted using phylogenetic investigation of communities by reconstruction of unobserved states 2 (PICRUSt 2) based on the Kyoto Encyclopedia of Genes and Genomes (KEGG; https://www.genome.jp/ kegg/) database (Langille et al., 2013). The STAMP software package (https://beikolab.cs.dal.ca/software/ STAMP) was used to identify microbial relevant functions between 7 different type of cheese, and it also can be used to generate principal components analysis based on the KEGG orthology from PICRUSt2 analysis (Parks et al., 2014). The $16 \mathrm{~S}$ rRNA sequences are available at the BioProject of the National Center for Biotechnology Information (https://www.ncbi.nlm.nih .gov/bioproject/; PRJNA753827).

\section{RESULTS}

\section{Chemical Composition}

Moisture, ash, fat, protein, and carbohydrate contents were analyzed for all concentrations of FOS, inulin, and control groups (Figure 2). The amount of carbohydrate was less than $5 \%$ of total composition in all groups, as the majority of carbohydrates present in milk was removed during the process of draining off whey (ANOVA, Tukey $P<0.05$ ). The moisture content of inulin-supplemented Cheddar cheeses $(45.10 \pm$ $2.61 \%)$ showed significant increase than $(P<0.05)$ the control $(40.59 \pm 0.38 \%)$ and FOS-supplemented Cheddar cheese $(40.25 \pm 1.82 \%)$. However, there were no significant differences between the ash, fat, or protein contents among all groups.

\section{Viable Bacteria}

Lactic acid bacteria counts and aerobic plate counts (APC) were measured throughout the cheese-making procedure: pasteurized milk, milk from $1 \mathrm{~h}$ after addition of SLAB, whey, curd, fresh cheese, and after 90 $\mathrm{d}$ of aging. The prevalence of LAB was analyzed on MRS medium and increased throughout the processing of cheese but decreased from the sample of fresh cheese to aged cheese (Figure 3A). The quantity of LAB (log $\mathrm{cfu} / \mathrm{g})$ in Cheddar cheese supplemented with FOS (6.34 \pm 0.11 and $8.99 \pm 0.46)$ and inulin $(6.02 \pm 0.79$ and $9.08 \pm 1.00)$ was significantly increased $(P<0.05)$ from the control $(5.84 \pm 0.27$ and $8.48 \pm 0.06)$ in whey and curd samples collected during processing, respectively. 
The presence of LAB in inulin-supplemented Cheddar cheese after $90 \mathrm{~d}$ aging decreased significantly compared with the control and FOS-supplemented Cheddar cheeses $(P<0.05)$. There were no significant changes in APC between the samples of fresh cheese and aged 90 d. Inulin-supplemented cheese $(2 \%)$ showed the highest level of APC after collection of the curd sample to fresh cheese but then decreased during aging, following the trend of the other analyzed samples. The final number of APC is a higher quantity than LAB as 3M Petri films allow the growth of a broader range of organisms as opposed to selectivity for LAB on MRS medium.

\section{Taxonomic Analysis}

Genus level analysis of taxonomy in FOS-supplemented cheese illustrated that relative abundance of Lactococcus spp. decreased throughout cheese-making procedure, whereas Streptococcus spp. increased (Figure 4B). The SLAB used for making all cheeses included Lactococcus and Streptococcus. The 2\% FOSsupplemented cheese (Figure 4B) exhibited a significantly higher relative abundance of Lactobacillaceae, nonstarter LAB (NSLAB), on the $90 \mathrm{~d}$ (ANOVA, Tukey $P<0.05)$. In analysis of the inulin-supplemented cheese (Figure 4C), the same trend was observed with higher abundance of Lactococcus spp. at the beginning of cheese-making procedure followed by an increase in Streptococcus. The 2\% inulin-supplemented cheese also exhibited a significantly higher relative abundance of NSLAB on the ample aged $90 \mathrm{~d}$ (ANOVA, Tukey $P<$ $0.05)$.

\section{Microbial Diversity}

Two different types of alpha diversity (Chao1 and Shannon) were analyzed (Figure 5). Based on the Chao 1 index which indicates the estimated number of species in a community, the sample of milk was rich in microbial diversity, however no significant differences were observed in other samples from $1 \mathrm{~h}$ after addition of starter cultures through $90 \mathrm{~d}$ aged cheese (Figure 5A). Using the Shannon index to account for both abundance and evenness of the species present in a community, no significant differences were observed between the control, FOS, and inulin treatments. In the cheese-making process, $1 \mathrm{~h}$ after SLAB was added, whey showed the lowest index, whereas milk demonstrated the highest index (Figure 5B).

Beta diversity was quantified using the Bray-Curtis model to identify any compositional dissimilarity between cheese batch, prebiotic treatment, and the steps of cheese production (Figure 6). No difference in beta diversity was found within batch (Figure 6A),
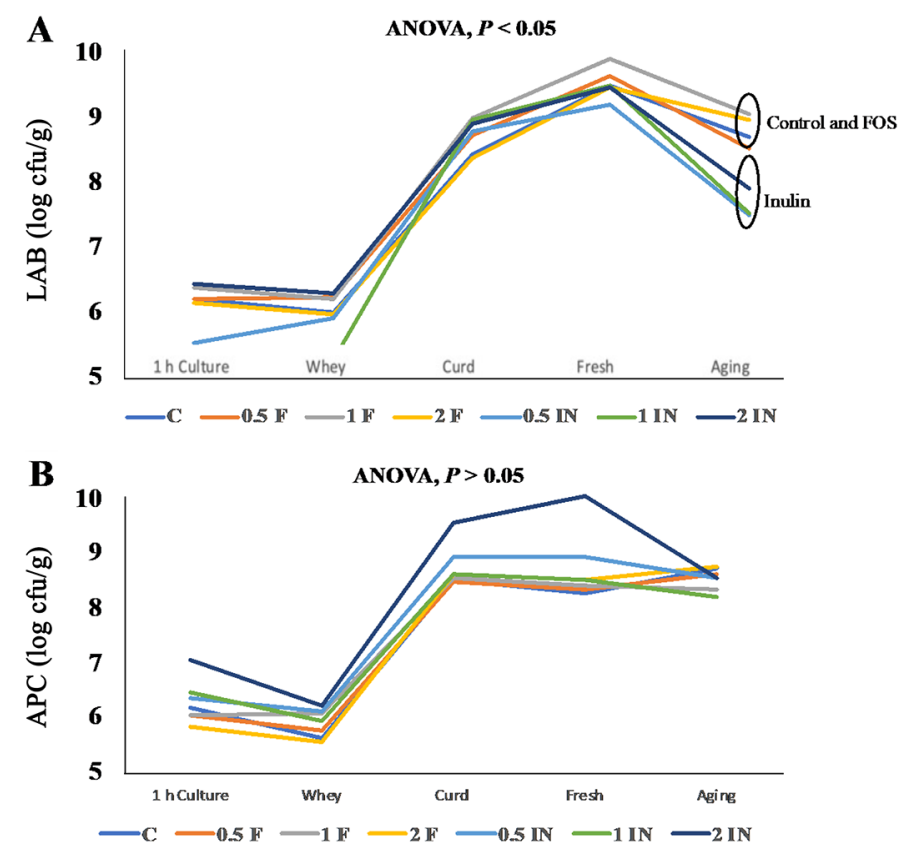

Figure 3. Viable counts of lactic acid bacteria (LAB) on de Man, Rogosa, and Sharpe medium (A) and aerobic bacteria (APC) on APC Petrifilm (3M) (B). Cheese samples were supplemented with the prebiotics fructooligosaccharide (FOS) or inulin at $0.5,1.0$, and $2.0 \%$ (wt/ wt). $\mathrm{C}=$ control; $0.5 \mathrm{~F}=0.5 \%$ FOS, $1 \mathrm{~F}=1 \%$ FOS; $2 \mathrm{~F}=2.0 \%$ FOS; 0.5 IN: $0.5 \%$ inulin, 1 IN: $1.0 \%$ inulin, 2 IN: $2.0 \%$ inulin.

whereas prebiotic treatment and cheese-making step showed significant difference (Figure $6 \mathrm{~B}$ and $6 \mathrm{C}$ ). In cheese-making steps, microbial community similarities changed chronologically, and milk had a significantly different microbial community compared with other steps (Figure 6C).

\section{Bacterial Functional Analyses}

Bacterial functional properties and their changes throughout the cheese production process were predicted using 16S rRNA marker genes based on PICRUSt2. Of all batches, $2 \%$ inulin-supplemented cheese showed the only significantly different functional properties (Figure 7). There was no significant difference between fresh and aged cheese until $20 \mathrm{~d}$ after aging (Figure 8A and $8 \mathrm{~B}$ ), whereas $2 \%$ inulin or $2 \%$ FOS-supplemented cheeses showed distinctively different functional properties after $60 \mathrm{~d}$ aging (Figure 8D and 8E).

\section{DISCUSSION}

Cheddar cheeses produced with added prebiotics were analyzed from the start of manufacturing with pasteurized milk through the end of 90-d aging period. Chemical compositions of all Cheddar cheeses are in line with previous findings of a study analyzing Cheddar style of 


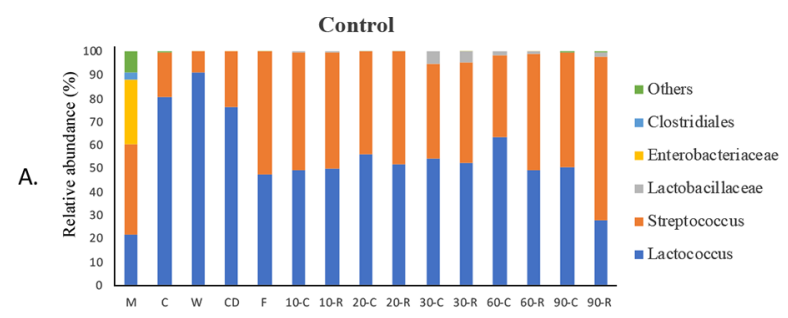

$0.5 \%$ FOS

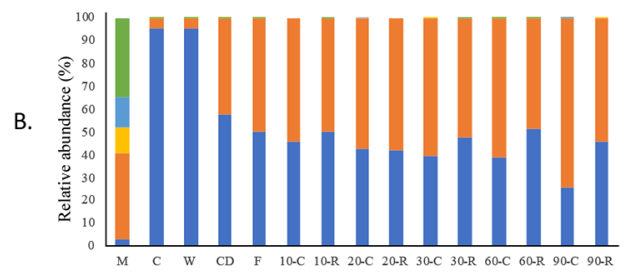

$0.5 \%$ Inulin
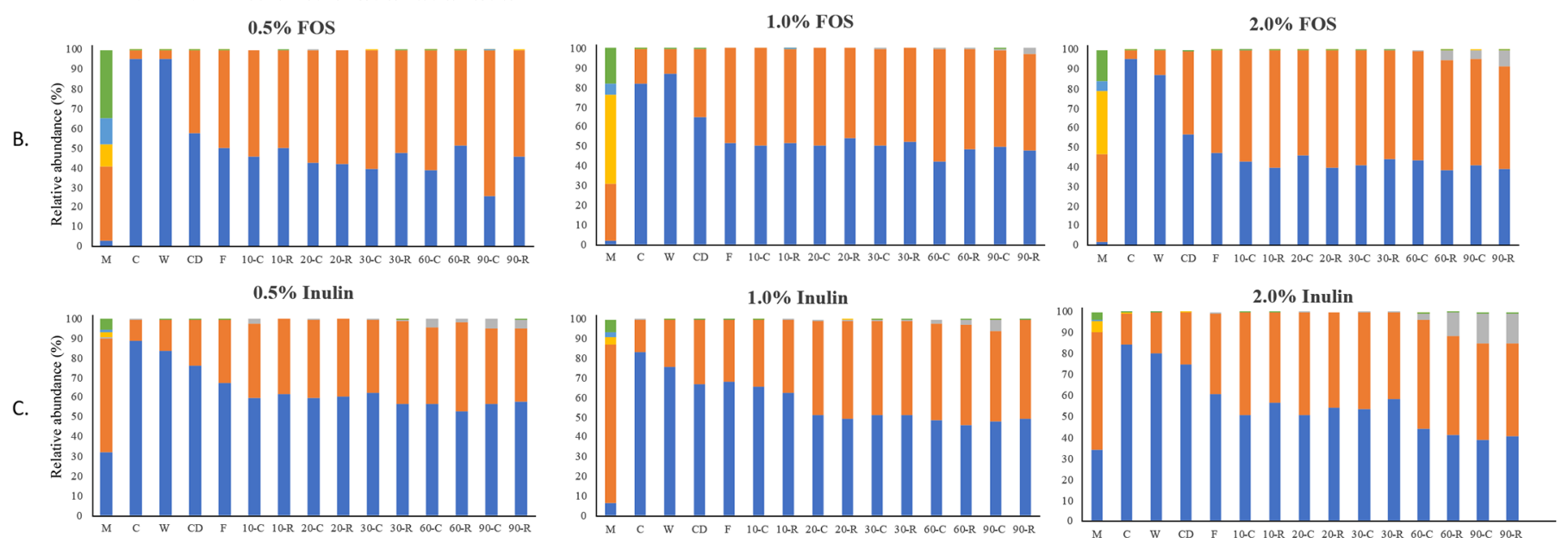

Figure 4. Taxonomic analysis for control and each prebiotic-supplemented cheese: control (A), fructooligosaccharides (FOS)-supplemented cheeses (B), and inulin-supplemented cheeses (C). Cheese samples were categorized as M (pasteurized milk), $\mathrm{C}$ (milk $1 \mathrm{~h}$ after addition of starter lactic acid bacteria, SLAB), W (whey), CD (curd), F (fresh cheese), 10C (10-d aged core), 10R (10-d aged rind), 20C (20-d aged core), 20R (20-d aged rind), 30C (30-d aged core), 30R (30-d aged rind), 60C (60-d aged core), 60C (60-d aged rind), 90C (90-d aged core), and 90R (90-d aged rind).

cheese supplemented with buttermilk powder (Hickey et al., 2017). The inulin-supplemented cheeses showed the highest moisture content across all concentrations compared with FOS-supplemented and control cheeses. This can be attributed to the capacity of inulin for gel formation, for which many food manufacturers have included inulin in gummy products or shelf stabilized beverages (Delgado and Bañón, 2018). In this study, inulin was added to the milk and heated to $32^{\circ} \mathrm{C}$, which activates the temperature gelling properties of the starch and allowed a tri-dimensional network to form with immobilized water suspending among insoluble crystalline particles. This property of inulin retaining water has allowed its addition as a fat substitution into mozzarella cheeses and fermented sausages up to a 10 $\mathrm{g} / 100 \mathrm{~g}$ (wt/wt) concentration without affecting aroma characteristics of the cheese (Hennelly et al., 2006). However, the Cheddar cheeses produced in this study was not standardized in protein-to-fat levels, which has been previously shown to affect final product moisture content (Guinee et al., 2007).

The predominant organisms present in all Cheddar cheeses in this study were Streptococcus spp. and Lactococcus spp., which were both included in the mesophilic starter cultures consisting of L. lactis ssp. lactis biovar diacetylactis, L. lactis ssp. lactis, L. lactis ssp. cremoris, and Strep. thermophilus. Relative abundance of Lactococcus was initially higher in the aged cheeses but decreased as Streptococcus inversely increased throughout the 90-d aging period. This initial low level of Streptococcus is largely responsible for acid production and formation of galactose during the cooking step of cheese making, and these strains then persist through aging as Lactococcus strains decrease due to higher salt sensitivity and extensive autolysis in cheese (Michel and Martley, 2001). The microbiota of Cheddar, a relatively firm and cooked cheese, is affected by moisture level; as more moisture is excluded out of the fat and protein matrix during aging, certain microorganisms such as Lactococcus decrease in the less desirable environment (Yeluri Jonnala et al. 2018). However, this higher moisture does have potential to allow for survival of undesirable organisms not typically found in Cheddar cheese, such as Salmonella either introduced in production or aging (Shrestha et al., 2011).

Nonstarter LAB was also detected in cheese samples, with significantly higher levels in the $2 \%$ FOS and $2 \%$ inulin-supplemented cheeses after $90 \mathrm{~d}$ of aging. Lactobacillaceae, the NSLAB identified in the $2 \%$ FOSsupplemented cheese, can often be used as an adjunct 
A

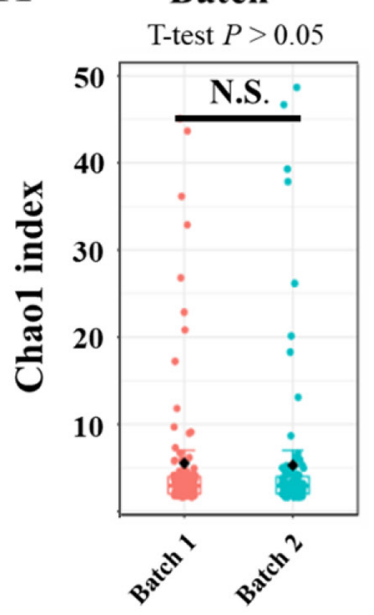

B

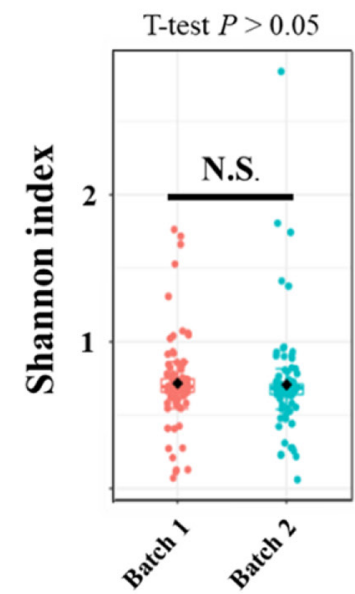

Prebiotic treatment

ANOVA, Tukey $P>0.05$

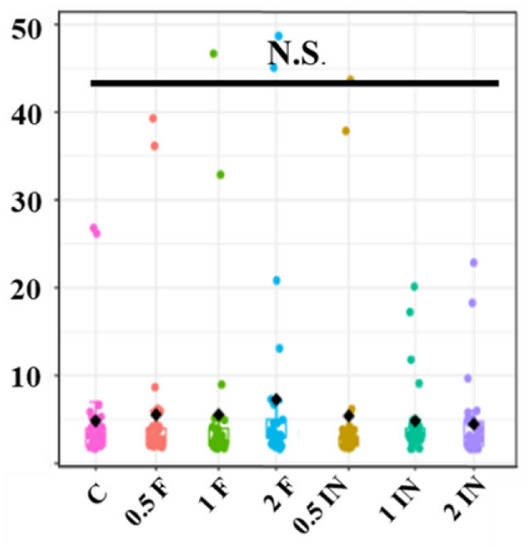

Prebiotic treatment

ANOVA, Tukey $P>0.05$

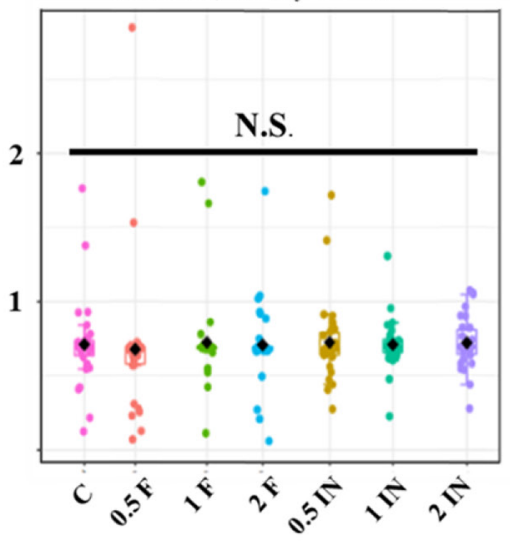

Cheese-making step

ANOVA, Tukey $P<0.05$

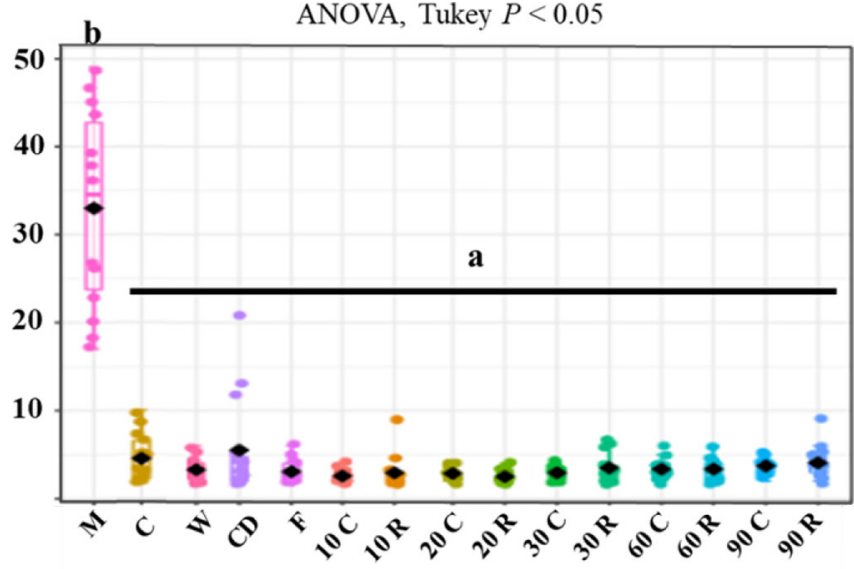

Cheese-making step

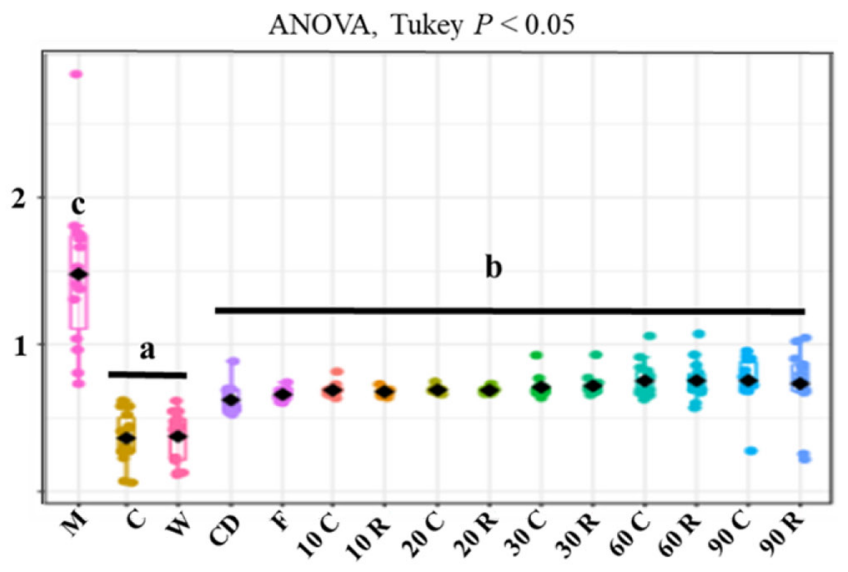

Figure 5. Alpha diversity analysis with Chao1 (A) and Shannon (B) indices. Prebiotic treatments: C $=$ control; $0.5 \mathrm{~F}=0.5 \%$ fructooligosaccharides (FOS); $1 \mathrm{~F}=1 \%$ FOS; $2 \mathrm{~F}=2.0 \%$ FOS; $0.5 \mathrm{IN}=0.5 \%$ inulin; $1 \mathrm{IN}=1.0 \%$ inulin; $2 \mathrm{IN}=2.0 \%$ inulin. Cheese-making samples were categorized as M (milk), C (milk $1 \mathrm{~h}$ after addition of starter lactic acid bacteria, SLAB), W (whey), CD (curd), F (fresh cheese), 10C (10-d aged core), 10R (10-d aged rind), 20C (20-d aged core), 20R (20-d aged rind), 30C (30-d aged core), 30R (30-d aged rind), 60C (60-d aged core), 60C (60-d aged rind), 90C (90-d aged core), and 90R (90-d aged rind). Batch replication denotes the duplicated production of each cheese group.

culture in cheeses to accelerate and improve texture and more desirable flavor during the cheese ripening process (Awad et al., 2007). Raw milk often is a predominant source of NSLAB in aged cheese, however as all samples in this study started with commercially pasteurized milk. These Lactobacillaceae likely entered the milk through environmental contamination as suggested by Choi et al. (2020b), may have been present environmentally, and persisted during the aging process. Although NSLAB can be responsible for undesirable flavor and physical defects in cheese such as abnormal flavor or lactate crystal formation, the presence of these organisms is also important for distinct desirable flavor development and maturation in different cheese types (Gobbetti et al., 2015). Commercial use of NSLAB in an adjunct starter can prevent variability between batches, as seen in this study, and has the potential to accelerate cheese aging time (Gobbetti et al., 2015). With increased moisture retention observed in inulinsupplemented cheeses and availability of a hexose substrate from FOS, these NSLAB would be able to persist longer throughout aging. Selected NSLAB may also have a competitive inhibition ability to pathogens potentially present in cheese, such as Listeria monocytogenes, through production of bacteriocins (Panebianco et al., 2021).

According to alpha diversity analyses with the Shannon index, no significant difference was found between prebiotic supplemented groups or batch replication of cheese. However, a significant difference was found 

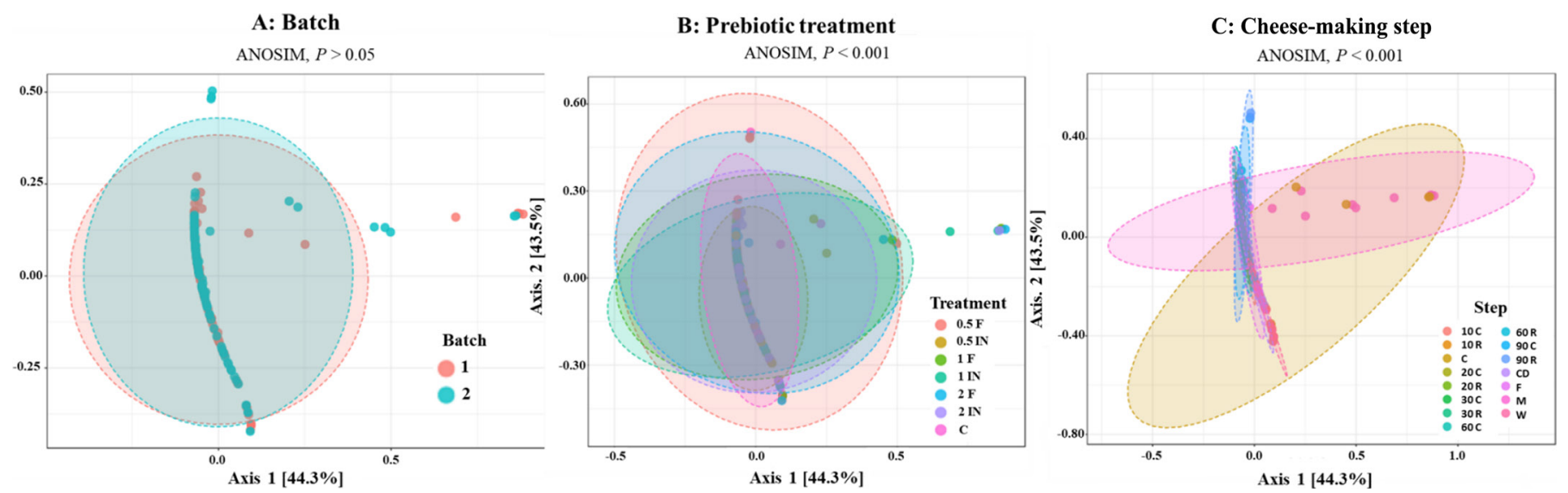

Figure 6. Beta diversity between production batch (A), prebiotic treatment (B), and cheese-making step (C) using the Bray-Curtis model. For panel $\mathrm{B}$, treatments were $\mathrm{C}=$ control; $0.5 \mathrm{~F}=0.5 \%$ FOS; $1 \mathrm{~F}=1 \% \mathrm{FOS} ; 2 \mathrm{~F}=2.0 \% \mathrm{FOS} ; 0.5 \mathrm{IN}=0.5 \%$ inulin; $1 \mathrm{IN}=1.0 \%$ inulin; 2 $\mathrm{IN}=2.0 \%$ inulin. For panel C, cheese samples were categorized as M (milk), C (milk $1 \mathrm{~h}$ after addition of starter lactic acid bacteria, SLAB), W (whey), and CD (curd), F (fresh cheese), 10C (10-d aged core), 10R (10-d aged rind), 20C (20-d aged core), 20R (20-d aged rind), 30C (30-d aged core), 30R (30-d aged rind), 60C (60-d aged core),60C (60-d aged rind), 90C (90-d aged core), 90R (90-d aged rind). Batch replication denotes the duplicated production of each cheese group.

throughout the production process, with 3 different groups of pasteurized milk, cultured milk and whey, and curds through $90 \mathrm{~d}$ of aging. This shift is consistent with the taxonomic analysis and viable plate counts performed and analyzed.

Using the Bray-Curtis model, beta diversity was found to be similar between the control and $0.5 \%$ FOSsupplemented cheeses and between $2 \%$ inulin and $2 \%$ FOS-supplemented cheeses (Figure 6B). Inulin has demonstrated a protective effect toward LAB, with the ability to maintain a higher viability of probiotic strains during storage of fermented products (Karimi et al., 2015). Inulin source, degree of polymerization, and length has an impact on the activity of starter and probiotic cultures, as well as the $\mathrm{pH}$ of the cheese (Karimi et al., 2015). Cheese supplemented with 2.0\% inulin had a significantly higher level of alpha and beta diversity, supporting both abundance and variety of microorganisms.

Differences in bacterial functional properties among groups of cheese (Figure 8) and any shifts occurring throughout the aging process were analyzed using $16 \mathrm{~S}$

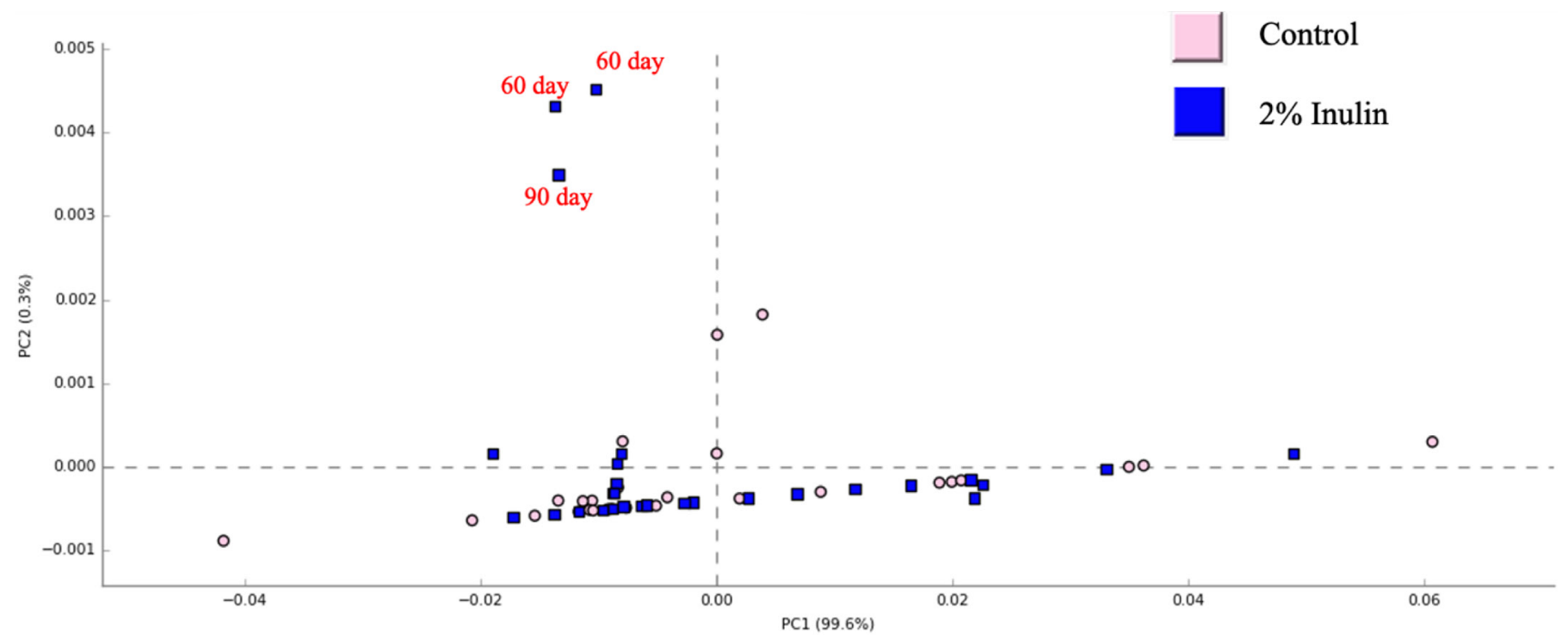

Figure 7. Plot of functional properties for control and $2 \%$ inulin-supplemented cheese throughout aging. Plot was generated based on $16 \mathrm{~S}$ rRNA marker genes, using PICRUSt2 (Parks et al., 2014). PC = principal component. 


\section{Functional properties (fresh vs. aging cheese)}

A.

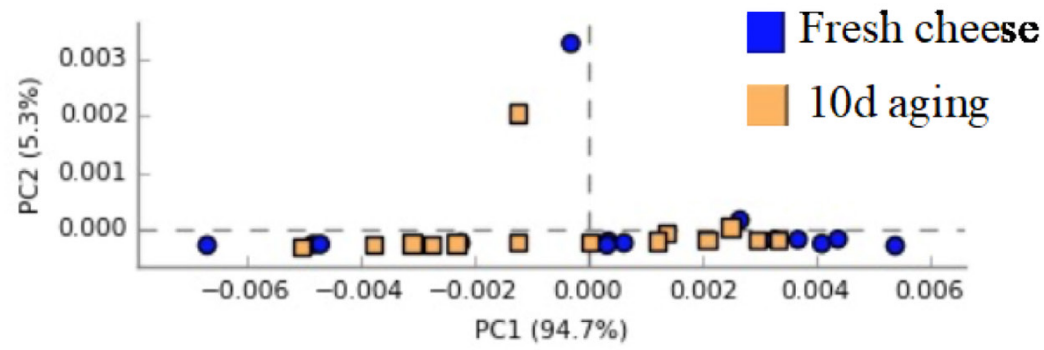

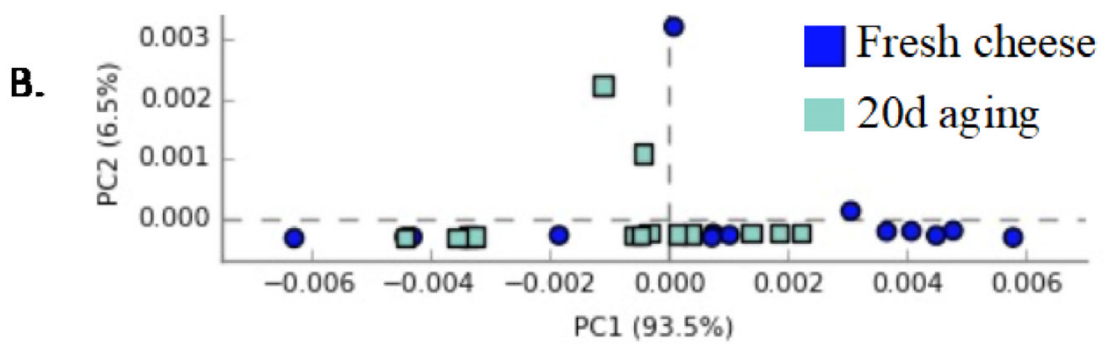

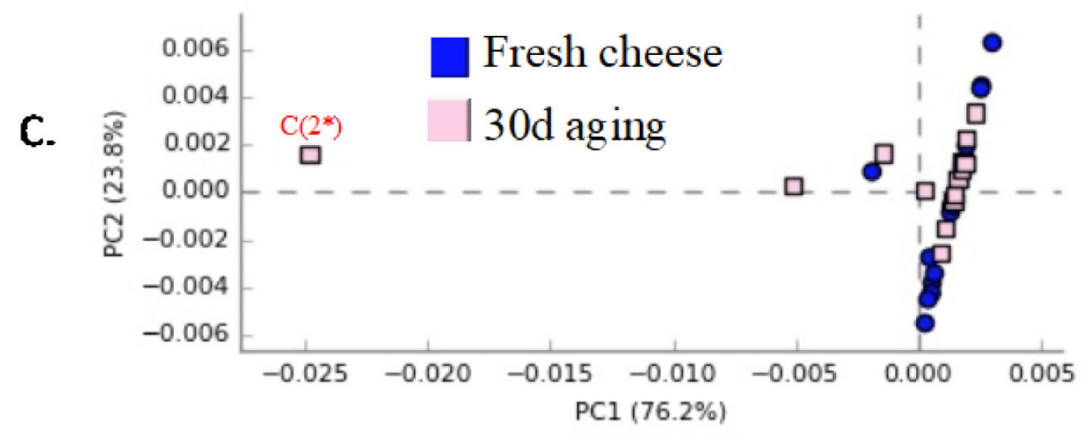

* indicates the first or second cheesemaking batch
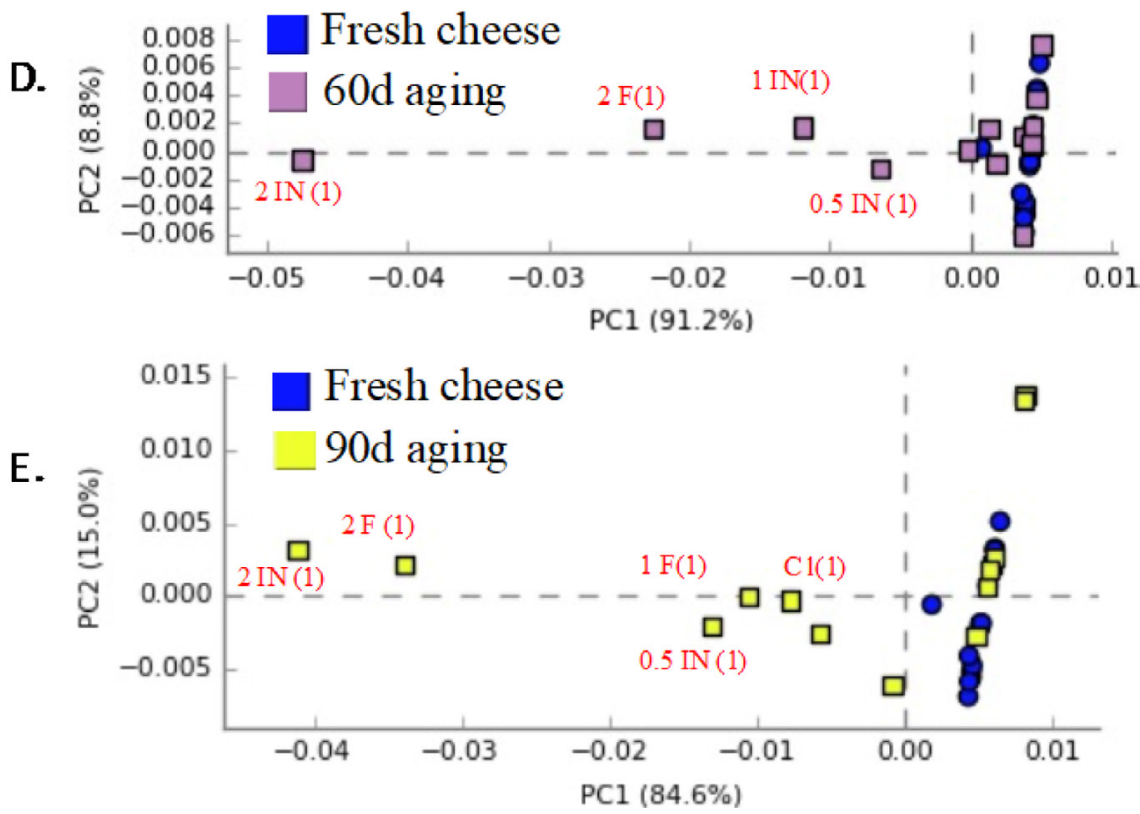

Figure 8. Functional properties plot for sampling at 10, 20,30,60, and $90 \mathrm{~d}$ of aging. Treatments: $\mathrm{C}=$ control, milk $1 \mathrm{~h}$ after addition of starter lactic acid bacteria, SLAB; $0.5 \mathrm{~F}=0.5 \%$ fructooligosaccharides (FOS); $1 \mathrm{~F}=1 \% \mathrm{FOS} ; 2 \mathrm{~F}=2.0 \% \mathrm{FOS} ; 0.5 \mathrm{IN}=0.5 \%$ inulin; $1 \mathrm{IN}=$ $1.0 \%$ inulin; $2 \mathrm{IN}=2.0 \%$ inulin. Plots were generated based on $16 \mathrm{~S}$ rRNA marker genes, using PICRUSt2 (Parks et al., 2014). PC $=$ principal component. 
rRNA marker genes using PICRUSt2. Throughout the aging process significant differences in functional properties emerged after $30 \mathrm{~d}$ and specifically a difference between the $2 \%$ inulin or $2 \%$ FOS-supplemented cheese groups. However, no significant difference was found in carbohydrate or amino acid metabolism between cheeses.

Nutritionally, inulin possesses several functions and health-enhancing effects in foods that include reduced caloric value as well as prebiotic effects (Saulnier et al., 2008) and can be used for various applications, including fat replacement, sugar, and texturizing agents (Rodríguez-García et al., 2014). Due to the inclusion of probiotic microorganisms in cheese this addition of inulin or FOS as a prebiotic is of particular interest for its synbiotic properties, providing a product that may promote sustained presence of beneficial bacteria such as Bifidobacterium in the human gut microbiota (Rosa et al., 2021). Presently, this study has not examined what amount of prebiotics remains in cheese after $90 \mathrm{~d}$ of aging and future experiments should examine if this prebiotic addition is beneficial to both the aging and consumption of Cheddar cheese. Although this study found limited differences between control, inulin, and FOS-supplemented cheeses, future research is needed to understand other applications in cheese products. The diversity of cheese manufacturing processes is important to consider when adding inulin. These considerations include length of the inulin, concentration, processing temperature, and shear rate and in turn, can affect moisture retention and sensory characteristics of cheese (Karimi et al., 2015). Additionally, Cheddar cheese in this experiment was aged for $90 \mathrm{~d}$, whereas Cheddar can traditionally be aged upwards of 8 to 10 mo.

This study provides an understanding of how prebiotics can affect the microbiome and chemical composition of cheeses, throughout the production and aging process. In this experiment we found that SLAB dominated the microbiome of cheese after inoculation, further research is needed to understand the emergence and stability of NSLAB in cheeses. Although this study explores the composition and potential probiotic benefits of prebiotic supplemented cheese, more elaborate investigation of the functional benefits and physiochemical characteristics should also be conducted to better understand the commercial applications of this value-added product.

\section{ACKNOWLEDGMENTS}

We thank Robin Frojen, Oregon State University Creamery Manager (Corvallis) for providing us equipment for small-scale cheese production and advice on recipe formulation. This research was partially support- ed by Oregon State University start-up funds awarded to Si Hong Park and BUILD (Building UniversityIndustry linkages through Learning and Discovery) Dairy Undergraduate Research Program to Melanie Hanlon. MH, JC, and SP designed research, conducted experiments, and analyzed the data and drafted the manuscript. MH, JC, LG, and SP wrote and critically reviewed the manuscript. All authors read and approved the manuscript. The authors have not stated any conflicts of interest.

\section{REFERENCES}

Al-Sheraji, S. H., A. Ismail, M. Y. Manap, S. Mustafa, R. M. Yusof, and F. A. Hassan. 2013. Prebiotics as functional foods: A review. J. Funct. Foods 5:1542-1553. https://doi.org/10.1016/j.jff.2013.08 .009 .

Awad, S., N. Ahmed, and M. E. Soda. 2007. Evaluation of isolated starter lactic acid bacteria in Ras cheese ripening and flavour development. Food Chem. 104:1192-1199. https://doi.org/10.1016/j .foodchem.2007.01.043.

Bolyen, E., J. R. Rideout, M. R. Dillon, N. A. Bokulich, C. C. Abnet, G. A. Al-Ghalith, H. Alexander, E. J. Alm, M. Arumugam, F. Asnicar, Y. Bai, J. E. Bisanz, K. Bittinger, A. Brejnrod, C. J. Brislawn, C. T. Brown, B. J. Callahan, A. M. Caraballo-Rodríguez, J. Chase, E. K. Cope, R. D. Silva, C. Diener, P. C. Dorrestein, G. M. Douglas, D. M. Durall, C. Duvallet, C. F. Edwardson, M. Ernst, M. Estaki, J. M. Gauglitz, S. M. Gibbons, D. L. Gibson, A. Gonzalez, K. Gorlick, J. Guo, B. Hillmann, S. Holmes, H. Holste, C. Huttenhower, G. A. Huttley, S. Janssen, A. K. Jarmusch, L. Jiang, B. D. Kaehler, K. B. Kang, C. R. Keefe, P. Keim, S. T. Kelley, D. Knights, I. Koester, T. Kosciolek, J. Kreps, M. G. I. Langille, J. Lee, R. Ley, Y. X. Liu, E. Loftfield, C. Lozupone, M. Maher, C. Marotz, B. D. Martin, D. McDonald, L. J. Mclver, A. V. Melnik, J. L. Metcalf, S. C. Morgan, J. T. Morton, A. T. Naimey, J. A. Navas-Molina, L. F. Nothias, S. B. Orchanian, T. Pearson, S. L. Peoples, D. Petras, M. L. Preuss, E. Pruesse, L. B. Rasmussen, A. Rivers, M. S. Robeson II, P. Rosenthal, N. Segata, M. Shaffer, A. Shiffer, R. Sinha, S. J. Song, J. R. Spear, A. D. Swafford, L. R. Thompson, P. J. Torres, P. Trinh, A. Tripathi, P. J. Turnbaugh, S. UI-Hasan, J. J. J. Hooft, F. Vargas, Y. Vázquez-Baeza, E. Vogtmann, M. Hippel, W. Walters, Y. Wan, M. Wang, J. Warren, K. C Weber, C. H. D. Williamson, A. D. Willis, Z. Z. Xu, J. R. Zaneveld, Y. Zhang, R. Knight, and J. G. Caporaso. 2019. Reproducible, interactive, scalable and extensible microbiome data science using QIIME 2. Nat. Biotechnol. 37:852-857. https://doi .org/10.1038/s41587-019-0209-9.

Choi, J., S. I. Lee, B. Rackerby, R. Frojen, L. Goddik, S. D. Ha, and S. H. Park. 2020b. Assessment of overall microbial community shift during Cheddar cheese production from raw milk to aging. Appl Microbiol. Biotechnol. 104:6249-6260. https://doi.org/10.1007/ s00253-020-10651-7.

Choi, J., S. I. Lee, B. Rackerby, L. Goddik, R. Frojen, S. D. Ha, J. H. Kim, and S. H. Park. 2020a. Microbial communities of a variety of cheeses and comparison between core and rind region of cheeses. J. Dairy Sci. 103:4026-4042. https://doi.org/10.3168/jds.2019-17455.

Delgado, P., and S. Bañón. 2018. Effects of replacing starch by inulin on the physicochemical, texture and sensory characteristics of gummy jellies. CYTA J. Food 16:1-10. https://doi.org/10.1080/ 19476337.2017.1327462.

Dhariwal, A., J. Chong, S. Habib, I. L. King, L. B. Agellon, and J. Xia. 2017. MicrobiomeAnalyst: A web-based tool for comprehensive statistical, visual and meta-analysis of microbiome data. Nucleic Acids Res. 45(W1):W180-W188. https://doi.org/10.1093/ nar/gkx295.

Dumas, J. B. A. 1831. Procedes de L'analyse Organique. Ann. Chim. Phys. 47:198-205. 
Gibson, G. R. 1998. Dietary modulation of the human gut microflora using prebiotics. Br. J. Nutr. 80(S2):S209-S212. https://doi.org/ 10.1017/S0007114500006048.

Gobbetti, M., M. De Angelis, R. Di Cagno, L. Mancini, and P. F. Fox. 2015. Pros and cons for using non-starter lactic acid bacteria (NSLAB) as secondary/adjunct starters for cheese ripening. Trends Food Sci. Technol. 45:167-178. https://doi.org/10.1016/j .tifs.2015.07.016.

Gosalvitr, P., R. Cuellar-Franca, R. Smith, and A. Azapagic. 2019. Energy demand and carbon footprint of cheddar cheese with energy recovery from cheese whey. Energy Procedia 161:10-16. https:// doi.org/10.1016/j.egypro.2019.02.052.

Guinee, T. P., E. O. Mulholland, J. Kelly, and D. J. O. Callaghan. 2007. Effect of protein-to-fat ratio of milk on the composition, manufacturing efficiency, and yield of cheddar cheese. J. Dairy Sci. 90:110-123. https://doi.org/10.3168/jds.S0022-0302(07)72613-9.

Hennelly, P. J., P. G. Dunne, M. O'Sullivan, and E. D. O'Riordan. 2006. Textural, rheological and microstructural properties of imitation cheese containing inulin. J. Food Eng. 75:388-395. https:// doi.org/10.1016/j.jfoodeng.2005.04.023.

Hickey, C. D., B. W. K. Diehl, M. Nuzzo, A. Millqvist-Feurby, M. G. Wilkinson, and J. J. Sheehan. 2017. Influence of buttermilk powder or buttermilk addition on phospholipid content, chemical and bio-chemical composition and bacterial viability in Cheddar style-cheese. Food Res. Int. 102:748-758. https://doi.org/10.1016/ j.foodres.2017.09.067.

ISO. 2008. Cheese - Determination of fat content - Van Gulik method. ISO 3433:2008. International Organization for Standardization.

Karimi, R., M. H. Azizi, M. Ghasemlou, and M. Vaziri. 2015. Application of inulin in cheese as prebiotic, fat replacer and texturizer: A review. Carbohydr. Polym. 119:85-100. https://doi.org/10.1016/j carbpol.2014.11.029.

Kozich, J. J., S. L. Westcott, N. T. Baxter, S. K. Highlander, and P. D. Schloss. 2013. Development of a dual-index sequencing strategy and curation pipeline for analyzing amplicon sequence data on the MiSeq Illumina sequencing platform. Appl. Environ. Microbiol. 79:5112-5120. https://doi.org/10.1128/AEM.01043-13.

Langille, M. G. I., J. Zaneveld, J. G. Caporaso, D. McDonald, D. Knights, J. A. Reyes, J. C. Clemente, D. E. Burkepile, R. L. Vega Thurber, R. Knight, R. G. Beiko, and C. Huttenhower. 2013. Predictive functional profiling of microbial communities using $16 \mathrm{~S}$ rRNA marker gene sequences. Nat. Biotechnol. 31:814-821. https: //doi.org/10.1038/nbt.2676.

Mayo, B., C. T. C. C. Rachid, A. Alegría, A. M. O. Leite, R. S. Peixoto, and S. Delgado. 2014. Impact of next generation sequencing techniques in food microbiology. Curr. Genomics 15:293-309. https://doi.org/10.2174/1389202915666140616233211.

Michel, V., and F. G. Martley. 2001. Streptococcus thermophilus in Cheddar cheese - production and fate of galactose. J. Dairy Res. 68:317-325. https://doi.org/10.1017/S0022029901004812.

Nam, J. H., Y. S. Cho, B. Rackerby, L. Goddik, and S. H. Park. 2021. Shifts of microbiota during cheese production: Impact on production and quality. Appl. Microbiol. Biotechnol. 105:2307-2318. https://doi.org/10.1007/s00253-021-11201-5.

OECD-FAO (OECD and Food and Agriculture Organization of the United Nations). 2021. OECD-FAO Agricultural Outlook 20212030. OECD Publishing. https://doi.org/10.1787/19991142.

Panebianco, F., F. Giarratana, A. Caridi, R. Sidari, A. de Bruno, and A. Giuffrida. 2021. Lactic acid bacteria isolated from traditional
Italian dairy products: Activity against Listeria monocytogenes and modelling of microbial competition in soft cheese. Lebensm. Wiss. Technol. 137:110446. https://doi.org/10.1016/j.lwt.2020 .110446 .

Parks, D. H., G. W. Tyson, P. Hugenholtz, and R. G. Beiko. 2014. STAMP: Statistical analysis of taxonomic and functional profiles. Bioinformatics 30:3123-3124. https://doi.org/10.1093/ bioinformatics/btu494.

Roberfroid, M. B. 1998. Prebiotics and synbiotics: Concepts and nutritional properties. Br. J. Nutr. 80(S2):S197-S202. https://doi.org/ $10.1017 /$ S0007114500006024.

Rocha, J. R., R. Catana, B. S. Ferreira, J. M. S. Cabral, and P. Fernandes. 2006. Design and characterisation of an enzyme system for inulin hydrolysis. Food Chem. 95:77-82. https://doi.org/10.1016/ j.foodchem.2004.12.020.

Rodríguez-García, J., A. Salvador, and I. Hernando. 2014. Replacing fat and sugar with inulin in cakes: Bubble size distribution, physical and sensory properties. Food Bioprocess Technol. 7:964-974. https://doi.org/10.1007/s11947-013-1066-z.

Rosa, M. C., M. R. S. Carmo, C. F. Balthazar, J. T. Guimarães, E. A. Esmerino, M. Q. Freitas, M. C. Silva, T. C. Pimentel, and A. G. Cruz. 2021. Dairy products with prebiotics: An overview of the health benefits, technological and sensory properties. Int. Dairy J. 117:105009. https://doi.org/10.1016/j.idairyj.2021.105009.

Saulnier, D. M. A., G. R. Gibson, and S. Kolida. 2008. In vitro effects of selected synbiotics on the human faecal microbiota composition. FEMS Microbiol. Ecol. 66:516-527. https://doi.org/10.1111/ j.1574-6941.2008.00561.x.

Shrestha, S., J. A. Grieder, D. J. McMahon, and B. A. Nummer. 2011. Survival of Salmonella serovars introduced as a post-aging contaminant during storage of low-salt Cheddar cheese at 4,10 and $21^{\circ}$ C. J. Food Sci. 76:M616-M621. https://doi.org/10.1111/j .1750-3841.2011.02430.x.

Solieri, L., T. C. Dakal, and P. Giudici. 2013. Next-generation sequencing and its potential impact on food microbial genomics. Ann. Microbiol. 63:21-37. https://doi.org/10.1007/s13213-012-0478-8.

Tejeda, H. A., and M. K. Kim. 2021. Dynamic price relationships and price discovery among cheese markets. Int. Food Agribus. Manag. Rev. 24:1-13. https://doi.org/10.22434/IFAMR2019.0206.

Vinderola, C. G., P. Mocchiutti, and J. A. Reinheimer. 2002. Interactions among lactic acid starter and probiotic bacteria used for fermented dairy products. J. Dairy Sci. 85:721-729. https://doi .org/10.3168/jds.S0022-0302(02)74129-5.

Widyastuti, Y., Rohmatussolihat, and A. Febrisiantosa. 2014. The role of lactic acid bacteria in milk fermentation. Food Nutr. Sci. 5:435-442. https://doi.org/10.4236/fns.2014.54051.

Yeluri Jonnala, B. R., P. L. H. McSweeney, J. J. Sheehan, and P. D. Cotter. 2018. Sequencing of the cheese microbiome and its relevance to industry. Front. Microbiol. 9:1020. https://doi.org/10 $.3389 /$ fmicb.2018.01020.

\section{ORCIDS}

Lisbeth Goddik @ https://orcid.org/0000-0002-3657-7173 Si Hong Park @ https://orcid.org/0000-0001-6587-7020 